\title{
Sensor properties of ZnO:Al nanofibres obtained by electrospinning*
}

\author{
Wojciech Maziarz ${ }^{\dagger}$, Artur Rydosz, Kinga Wysocka, Tadeusz Pisarkiewicz \\ AGH University of Science and Technology, Faculty of Computer Science, Electronics and Telecommunications, \\ Dept. of Electronics, Al. Mickiewicza 30, 30-059 Kraków
}

\begin{abstract}
An electrospinning technology have been developed to obtain zinc oxide nanofibres doped with aluminum. Properties of the obtained nanostructures can be controlled by both the composition of a precursor and subsequent annealing treatment. The gas sensors manufactured with the use of $\mathrm{ZnO}: \mathrm{Al}$ nanofibres exhibit good response to $\mathrm{NO}_{2}$ at relatively low operating temperatures. For some samples it was observed that interaction with ambient $\mathrm{NO}_{2}$ gas causes the change of conductivity from n-type to p-type at higher operating temperatures. This phenomenon was not observed for the samples annealed at higher temperature.
\end{abstract}

Keywords: ZnO:Al nanofibres; electrospinning; gas sensors

(C) Wroclaw University of Technology.

\section{Introduction}

Zinc oxide is a direct wide band gap semiconductor (3.37 eV at room temperature) with a high exciton binding energy $(60 \mathrm{meV})$, important in applications in optoelectronics, nanoelectronics and sensor technology (overview of $\mathrm{ZnO}$ materials and devices is given in [1]). Some optoelectronic applications of $\mathrm{ZnO}$ overlap with applications of another wide bandgap semiconductor, i.e. $\mathrm{GaN}$, which is widely used for production of green, blue, ultraviolet, and white light-emitting devices. However, $\mathrm{ZnO}$ with its large exciton binding energy and much simpler crystal-growth technology, resulting in a potentially lower cost for $\mathrm{ZnO}$-based devices, has some advantages over GaN. Another recently investigated application of $\mathrm{ZnO}$ is the fabrication of transparent thin-film transistors, which due to their wide bandgap are insensitive to visible light. By controlling the doping level electrical properties of $\mathrm{ZnO}$ can be changed from insulator, through n-type semiconductor, to metal, maintain-

\footnotetext{
*This paper was presented at the $37^{\text {th }}$ International Microelectronics and Packaging Conference IMAPS-CPMT Poland 2013, 22 - 25 September, 2013, Kraków.

†E-mail: maziarz@agh.edu.pl
}

ing at the same time a good optical transparency what makes it useful for transparent electrodes in flat-panel displays and solar cells.

Quite recently investigated one-dimensional $\mathrm{ZnO}$ nanostructures such as nanorods, nanobelts, nanotubes, nanowires, owing to their increased role of the surface, attracted increasing research interest, in particular, for applications as gas sensors [25]. Growing of nanostructured $\mathrm{ZnO}$ can be accomplished by adopting a number of techniques [6, 7]. Among them the electrospinning provides a simple, straightforward way to fabricate one-dimensional materials with easy control and low cost [8-10].

The properties of $\mathrm{ZnO}$, even in the undoped state, are often affected by intrinsic defects such as oxygen vacancies $\left(\mathrm{V}_{O}\right)$ or $\mathrm{Zn}$ interstitials $\left(\mathrm{Zn}_{i}\right)$. The intrinsic defects mentioned above cause ntype conductivity. A pure zinc oxide is unstable in air and the absorbed gases $\left(\mathrm{O}_{2}, \mathrm{CO}_{2}\right)$ and water vapour influence its electrical properties. Therefore in many investigations one tries to dope this material intentionally to improve its properties. For n-type doping one uses typically group III elements as $\mathrm{Al}, \mathrm{Ga}$, and $\mathrm{In}$, which substitute $\mathrm{Zn}$ in the lattice.

The absence of reliable p-type doping is the major bottleneck limiting the development of various 
types of bipolar $\mathrm{ZnO}$-based devices, including light emitting and laser diodes. The p-type problem has been mainly ascribed to self-compensation of acceptors by native donor defects $\left(\mathrm{V}_{O}\right)$ and $\left(\mathrm{Zn}_{i}\right)$ and donor-type complexes $\left(\mathrm{N}_{2}\right.$ on $\mathrm{O}$ sites) but also low acceptor dopant solubility. Additionally, an incorporation of hydrogen donors from the growth environment may influence the p-type doping process. Most of the investigations concentrate on mono acceptor doping. Group-I elements (Li, K) essentially substitute $\mathrm{Zn}$ sites giving shallow acceptors but having small atomic radius easily occupy interstitial positions acting mainly as donors what causes compensation [11]. Another group of p-type dopants investigated are group-V elements $(\mathrm{N}, \mathrm{P}$, $\mathrm{As}, \mathrm{Sb}$ ) [12-14], which are expected to generate acceptor states if incorporated substitutionally onto the oxygen sites. The most suitable dopant here is nitrogen, as it has nearly the same ionic radius as oxygen. However, the elements from group V can also substitute $\mathrm{Zn}$, which in this case leads to n-type conductivity. Typical example here is the high electron concentration obtained in thin films of $\mathrm{ZnO}: \mathrm{Sb}$ grown by MBE [15]. In general, the main problem of all above mentioned doping approaches is their lack of reproducibility. To improve the p-type doping process and to better control the conductivity one tries sometimes to develop the codoping procedures, where both donor and acceptor dopants as $\mathrm{Al}-\mathrm{N}$ [16] or In-N [17] are introduced.

The authors doped the manufactured $\mathrm{ZnO}$ nanofibres with $\mathrm{Al}$ (n-type doping), to lower their high resistivity and make resistance measurements of the investigated sensors easier. However, interaction of the nanofibres with the investigated gas, in our case $\mathrm{NO}_{2}$, caused that at elevated temperatures the samples obtained at selected manufacturing conditions (composition of precursor, annealing temperature) changed the conductivity to $\mathrm{p}$ type. This seems to be quite new experimental result in literature for the $\mathrm{ZnO}$ nanofibres obtained by electrospinning.

\section{Experimental}

The samples in a form of nanofibres were obtained with the help of the electrospinning de-

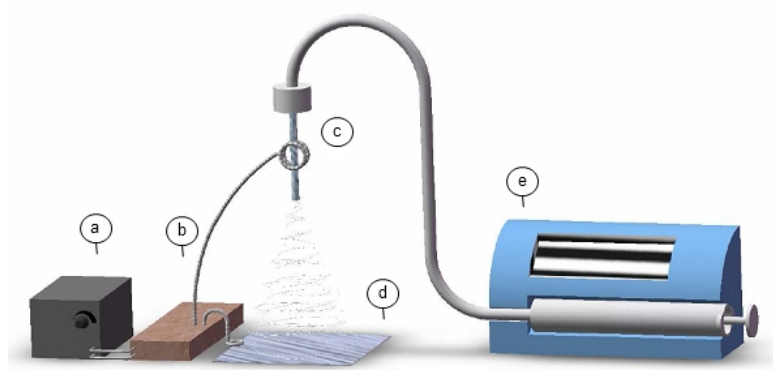

Fig. 1. A schematic view of the setup for the electrospinning: (a) high voltage power supply, (b) voltage multiplier, (c) dosing needle $(+),(d)$ collecting plate (grounded), (e) dosing syringe pump.

vice presented in Fig. 1. The manufacturing process can be divided into three stages: preparation of a precursor solution, process of the electrospinning, and annealing of as-obtained fibres. The precursor material was prepared using the following constituents: aluminum nitrate $\mathrm{Al}\left(\mathrm{NO}_{3}\right)_{3}(99,997 \%$, Aldrich), polyvinyl alcohol (8 - 88 PVA, Mw $\sim 67000$, Aldrich), zinc acetate $\mathrm{Zn}\left(\mathrm{CH}_{3} \mathrm{COO}\right)_{2} \cdot 2 \mathrm{H}_{2} \mathrm{O}$ (Chempur), and distilled water. The constituents were mixed for $2 \mathrm{~h}$ at $60{ }^{\circ} \mathrm{C}$ and then cooled down to room temperature (RT) for $2 \mathrm{~h}$. The obtained solution was introduced to the dosing pump and the electrospinning was performed by applying the high voltage of order $9 \mathrm{kV}$. The distance between the needle tip and the collecting plate, influencing the electric field strength, was adjusted experimentally. Obtained nanofibres were annealed at selected temperatures $\left(600{ }^{\circ} \mathrm{C}, 700{ }^{\circ} \mathrm{C}\right.$, $800{ }^{\circ} \mathrm{C}, 900{ }^{\circ} \mathrm{C}$ ) for $0.5 \mathrm{~h}$ in air and then cooled down to RT during $5 \mathrm{~h}$.

The fibres shown in Fig. 2 were obtained from the solution consisting of $70 \%$ water, $11.5 \%$ PVA, and $18.5 \%$ salts (labeled E02). The annealing of the nanofibres caused decomposition and burnout of PVA and a formation of $\mathrm{ZnO}$ oxide doped with Al. Diffraction experiments were performed using a X'Pert MPD Philips spectrometer with $\mathrm{Cu} \mathrm{K} \alpha$ radiation $(1.5418 \AA$ ), by a constant angle method $\left(\omega=3^{\circ}\right)$. The analysis of XRD spectrum with X'Pert HighScore Plus software and comparison of distinguished peaks and their 


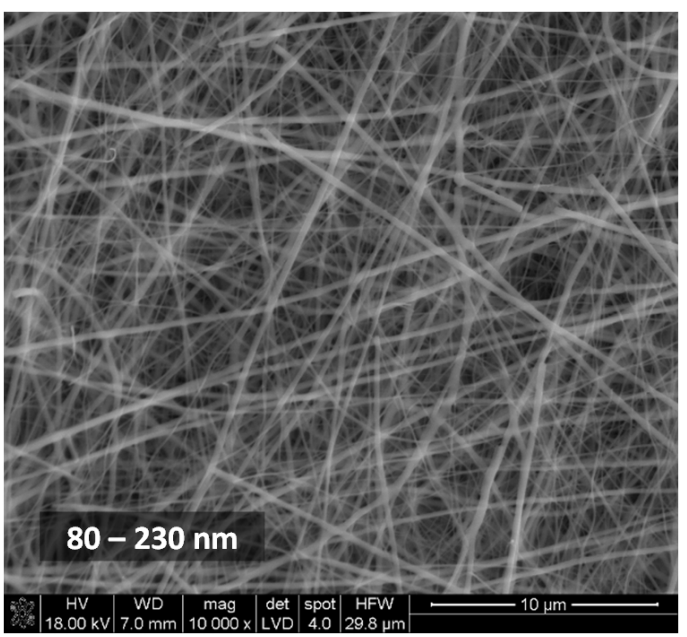

(a)

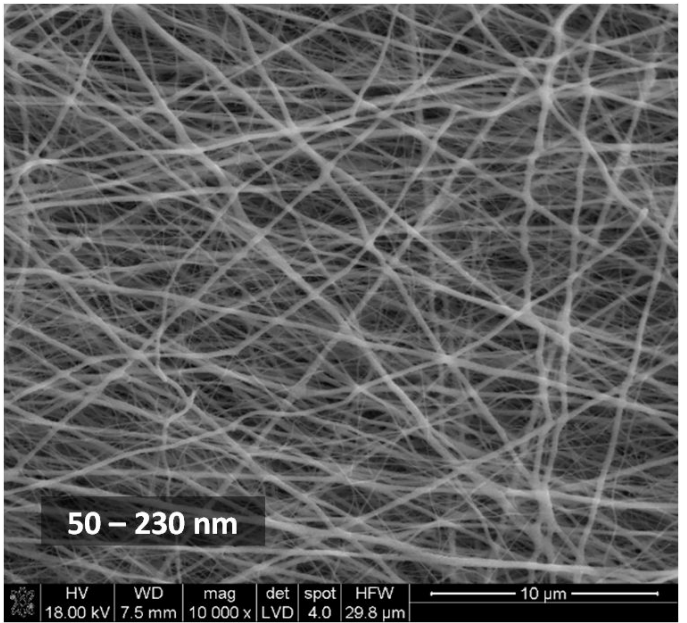

(b)

Fig. 2. SEM images of nanofibres obtained from precursor E02 and annealed at (a) $600{ }^{\circ} \mathrm{C}$ and (b) $900{ }^{\circ} \mathrm{C}$. The diameters of obtained nanofibres are shown.

intensity with database showed the best fit to $\mathrm{ZnO}$ hexagonal wurtzite structure (card reference number: 00-005-0664), Fig. 3. The measurements indicate that the nanofibres consist only of $\mathrm{ZnO}$ and indicate that all polymer was removed during annealing process.

\section{Results and discussion}

The sensitivity of manufactured sensors (planar structure of nanofibre bundles with gold electrodes) in response to nitrogen dioxide was investigated as

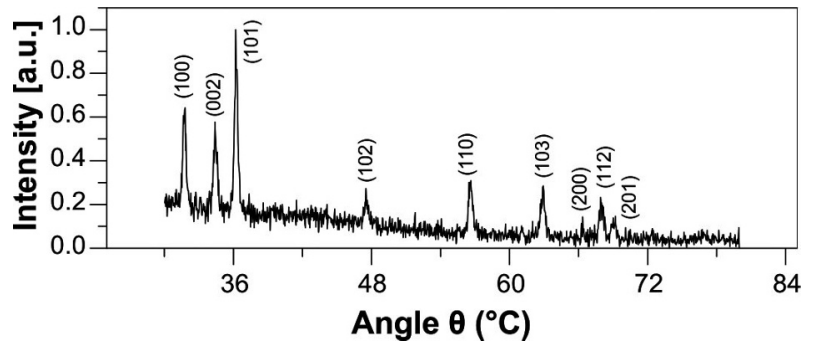

Fig. 3. XRD spectrum of sample E02S900.
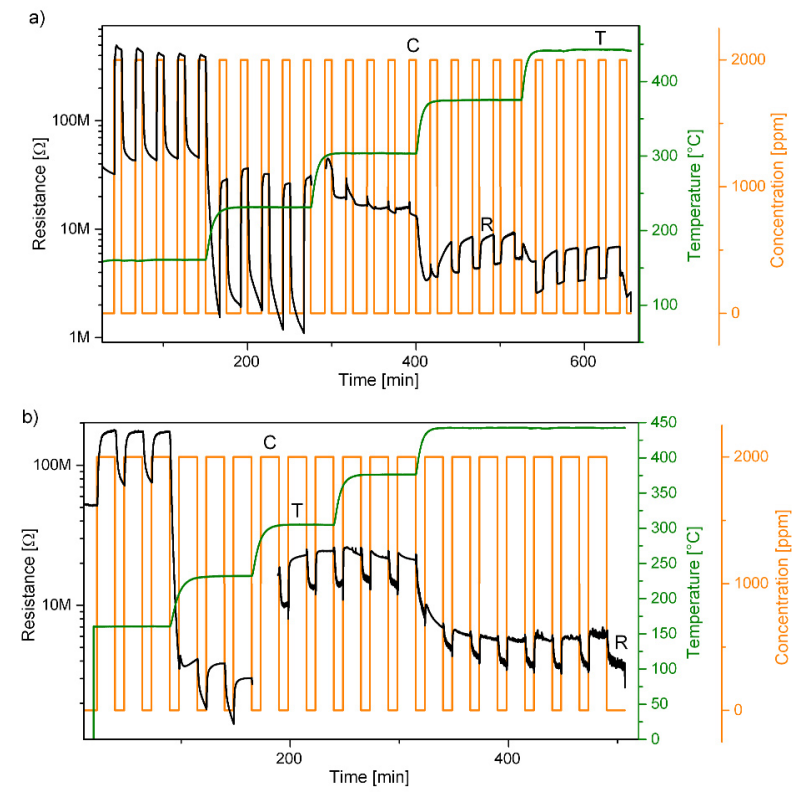

Fig. 4. Variation of resistance $\mathrm{R}$ after exposure to $\mathrm{NO}_{2}$ for $\mathrm{ZnO}$ :Al nanofibres at varying operating temperature $\mathrm{T}$ and gas concentration $\mathrm{C}$ : (a) sample E01S600, (b) sample E01S900.

a function of gas concentration at selected operating temperatures. A resistance of the sensors was measured using Keithley 6517 electrometer working in the voltage source mode. Essentially two types of behaviour were observed, Fig. 4. As can be seen in Fig. 4a the sample E01S600 (consisting of fibres annealed at $600{ }^{\circ} \mathrm{C}$ ) at operating temperatures lower than ca. $250{ }^{\circ} \mathrm{C}$ behaves as a typical n-type semiconductor in an oxidizing gas atmosphere, in this case $\mathrm{NO}_{2}$, i.e. the sample resistance increases in presence of the gas. However, as the operating temperature exceeds $350{ }^{\circ} \mathrm{C}$, the sample behaves as a p-type semiconductor, decreas- 


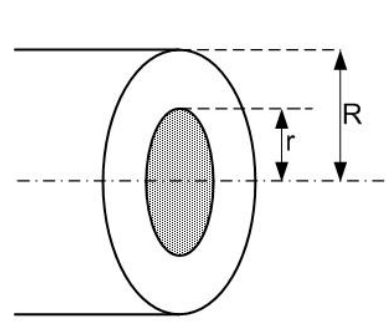

(a)

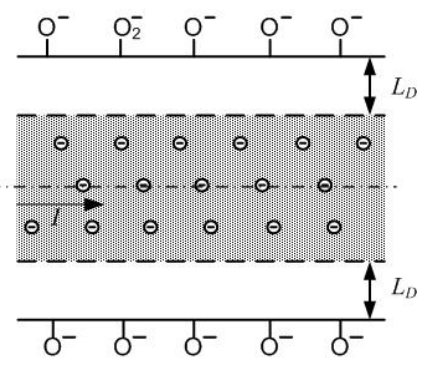

(b)
Fig. 5. A single nanowire of radius $R$ (a) with a depleted region of thickness $\mathrm{L}_{D}$ (Debye length) connected with surface oxygen traps (b).

ing its resistance in presence of the oxidizing gas. Sample E01S900 in Fig. 4b, which consists of the fibres annealed at $900{ }^{\circ} \mathrm{C}$, behaves as a n-type semiconductor for all the operating temperature ranges. The possible explanation of this behaviour is that the sample annealed at lower temperature $\left(600^{\circ} \mathrm{C}\right)$, under influence of the ambient $\mathrm{NO}_{2}$ gas containing nitrogen, changes its conductivity to p-type. Intentional doping of $\mathrm{ZnO}$ with the nitrogen, leading to p-type conductivity is known, as was mentioned in the introduction.

The observed behavior of the nanofibres conductance under the influence of a gas atmosphere can be explained by the known barrier model [18], which can be adopted to the nanowire geometry, as shown in Fig. 5. Oxygen molecules are chemisorbed on the semiconductor surface and, being acceptor centres, capture electrons from the semiconductor conduction band. In this case the surface depletion region (for n-type semiconductor) of thickness $\mathrm{L}_{D}$ is formed, Fig. 5b. The double charge layer gives rise to the formation of a surface barrier and transition of carriers to oxygen traps saturates. The chemisorption reaction between a surface centre $\mathrm{S}$ and oxygen (formation of a trap) and then the capture of a free electron (ionosorption) can be written as follows:

$$
\mathrm{S}+e^{-}+\frac{1}{2} \mathrm{O}_{2} \stackrel{k_{1}, k_{-1}}{\longleftrightarrow} \mathrm{O}_{S}^{-}
$$

where constants $\mathrm{k}_{1}, \mathrm{k}_{-1}$ and $\mathrm{k}_{2}$ describe the reaction rates. Introducing to the semiconductor ambient a gas with reducing properties, e.g. $\mathrm{CO}$, leads to the reaction of the gas with oxygen traps and release of the free electron:

$$
\mathrm{O}_{S}^{-}+\mathrm{R} \stackrel{k_{2}}{\longrightarrow} \mathrm{RO}+e^{-}
$$

In reaction (2) R stands for the reducing gas. In this case the conductivity increases. Using an oxidizing gas atmosphere, e.g. $\mathrm{NO}_{2}$, the concentration of surface traps increases and conductivity of a semiconductor decreases:

$$
\mathrm{NO}_{2, a d s}+e^{-} \leftrightarrow \mathrm{NO}_{2, a d s}^{-}
$$

The change in conductance can be calculated using a simple geometric model of a nanowire, Fig. 5. In this case one can assume that the only conduction channel is a cylinder of a radius $r$ and the depletion surface region does not contain free carriers. The ratio of the conductance of a cylindrical wire with a conducting inner channel (conductance $\mathrm{G}_{D}$ ) and a nanowire without oxygen traps (conductance $\mathrm{G}_{N W}$ ) is equal to:

$$
\frac{G_{D}}{G_{N W}}=\frac{\sigma \frac{\pi r^{2}}{L}}{\sigma \frac{\pi R^{2}}{L}}=\left(\frac{r}{R}\right)^{2}=\left(\frac{R-L_{D}}{R}\right)^{2}
$$

where $L$ is a nanowire length and $\sigma$ is the conductivity. As it can be seen from (4) when $\mathrm{L}_{D}$ increases, the sample conductance decreases. This model can be essentially applied to the homogeneous monocrystalline nanowire. When a nanowire consists of polycrystals, a change in its conductivity with concentration of an ambient gas is faster, as the intercrystalline barriers additionally influence the conduction.

The discussion above applies to n-type semiconductors. For a p-type material, surface oxygen traps are the cause of conductivity enhancement of the surface region as the compensation lowers. In this case one observes the inverse behavior for the interaction with ambient gases. Using $\mathrm{CO}$ one observes the decrease in the conductance. For $\mathrm{NO}_{2}$ atmosphere the conductance increases, as was observed by the authors in the experiment shown in Fig. 4a.

Further investigation of the observed behavior is however necessary. 


\section{Conclusions}

The method of electrospinning is a simple and low cost procedure, allowing fast deposition of the nanofibres. The $\mathrm{ZnO}$ nanofibres can be effectively doped with $\mathrm{Al}$ by electrospinning and the subsequent annealing treatment. The gas sensors manufactured with the use of $\mathrm{ZnO}: \mathrm{Al}$ nanofibres exhibit good response to $\mathrm{NO}_{2}$ at relatively low operating temperatures comparing to the conventional metal oxide sensors. For some samples it was observed that interaction with the ambient gas causes the change of conductivity from n-type to p-type at higher working temperatures. This phenomenon was not observed for samples annealed at higher temperature, e.g. $900{ }^{\circ} \mathrm{C}$, where we expect a formation of more "tight" polycrystalline structure, which makes the diffusion of the dopant atoms more difficult. Possibility of easy doping of gas sensitive material, leading to two conductivity types, may be utilised for the manufacturing of the junction-type sensor structures.

\section{Acknowledgements}

The work was supported in part by Polish Ministry of Science and Higher Education - WIET AGH statutory activity and in part by European Institute of Innovation and Technology under the KIC InnoEnergy New Mat Project.

\section{References}

[1] ÖZgür Ü. Alivov YA.I., LIU C., TEKe A., Reshchikov M.A., DoĞan S., Avrutin V., Cho S.-J., Morkoç H., J. Appl. Phys., 98 (2005), 041301.

[2] WEI A. et al., Mater. Sci. Eng. B-Adv., 176 (2011), 1409.
[3] Shouli B., Liangyuan CH. et al., Sensor. Actuat. BChem., 146 (2010), 129.

[4] Huang J., Wan Q., Sensors-Basel., 9 (2009), 9903.

[5] Maziarz W., Rydosz A., Pisarkiewicz T., Domański K., Grabiec P., Procedia Engineering, 47 (2012), 841.

[6] Fan H.J., Werner P., Zachariasz M., Small, 6 (2006), 700.

[7] Pisarkiewicz T., Kenig T., Rydosz A., Maziarz W., B. Pol. Acad. Sci.-Tech., 59 (2011), 425.

[8] Zhou B., Wu Y., Wu L., Zou K., Gai H., Physica E, 41 (2009), 705.

[9] Lotus A., KAng Y.C., WALKeR J.I., RAMSIER R.D., Chase G.G., Mater. Sci. Eng. B-Adv., 166 (2010), 61.

[10] WysockA K., MSc Thesis, 2013, AGH UST, Krakow, Poland.

[11] Lee E.-C., Chang K.J., Physica B, 376 - 377 (2006), 707.

[12] Lin C.C., Chen H.P., Chen S.Y., Chem. Phys. Lett., 404 (2005), 30.

[13] Su S.C., YAng X.D., Hu C.D., Physica B, 406 (2011), 1533.

[14] Mandalapu L.J., XiU F.X., Yang Z., LiU J.L., J. Appl. Phys., 102 (2007), 023716.

[15] LIU H.Y., IZYUMSKAYA N., AVRUTIN V., ÖZGÜR Ü., YankovichA.B. Et Al., J. Appl. Phys., 112 (2012), 033706.

[16] Lu J.G., Ye Z.Z., Zhu L.P., Zhuge F., Zhao B.H., HUANG J.Y., WANG L., JUAN J., J. Cryst. Growth, 283 (2005), 413.

[17] Chen L.L., Ye Z.Z., Lu J.G., Chu P.K., Appl. Phys. Lett. 89 (2006) 252113.

[18] Morrison S.R., The Chemical Physics of Surfaces, $1^{\text {st }}$ Edition, Plenum Press, New York, 1977.

Received 2013-10-14 Accepted 2014-03-12 